Provided for non-commercial research and education use. Not for reproduction, distribution or commercial use.

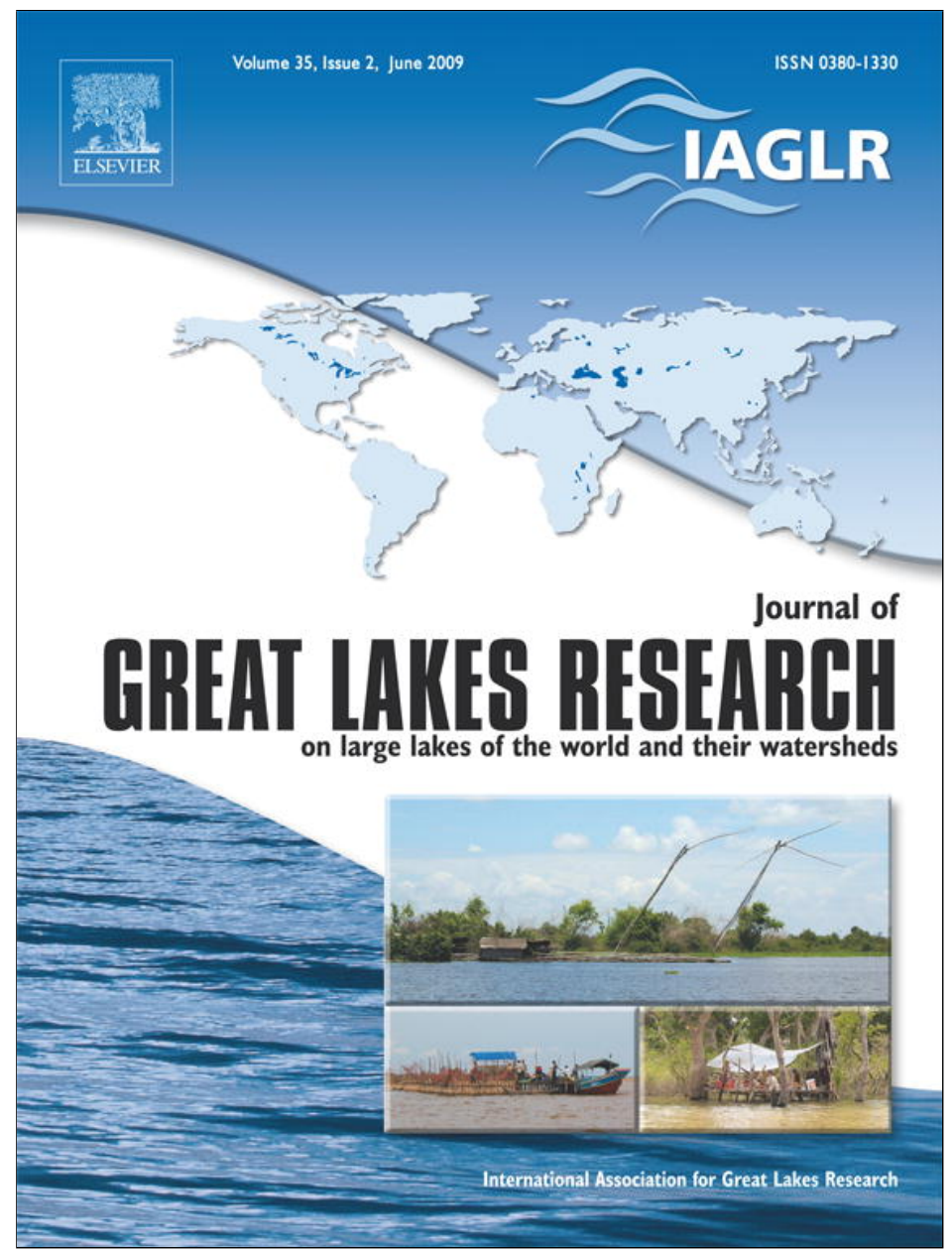

This article appeared in a journal published by Elsevier. The attached copy is furnished to the author for internal non-commercial research and education use, including for instruction at the authors institution and sharing with colleagues.

Other uses, including reproduction and distribution, or selling or licensing copies, or posting to personal, institutional or third party websites are prohibited.

In most cases authors are permitted to post their version of the article (e.g. in Word or Tex form) to their personal website or institutional repository. Authors requiring further information regarding Elsevier's archiving and manuscript policies are encouraged to visit:

http://www.elsevier.com/copyright 


\title{
Multiple male reproductive morphs in the invasive round goby (Apollonia melanostoma)
}

\author{
Julie R. Marentette ${ }^{\mathrm{a}, *}$, John L. Fitzpatrick ${ }^{\mathrm{b}, 1}$, Robert G. Berger ${ }^{\mathrm{a}, 2}$, Sigal Balshine ${ }^{\mathrm{a}, 3}$ \\ a Department of Psychology, Neuroscience and Behaviour, McMaster University, 1280 Main West, Hamilton, ON L8S 4L8, Canada \\ ${ }^{\mathrm{b}}$ Centre for Evolutionary Biology, School of Animal Biology, University of Western Australia, Crowley, Australia
}

\section{A R T I C L E I N F O}

\section{Article history:}

Received 11 September 2008

Accepted 26 January 2009

Communicated by Geoffrey Steinhart

\section{Index words:}

Sperm characteristics

Morphology

Androgens

Round goby

Invasive species

Reproductive tactics

\begin{abstract}
A B S T R A C T
Alternative male reproductive tactics are taxonomically widespread. In such species, parental, or conventional, males express secondary sexual characteristics, court females and guard offspring, while smaller parasitic or sneaker males avoid the costs of courtship and parental care by performing sneak fertilizations. Theory predicts that sneakers will invest more in testes mass and produce more competitive ejaculates than parentals because sneakers always experience sperm competition while parental males experience sperm competition only when a sneaker is present. Here we present convergent lines of evidence supporting the existence of alternative male reproductive tactics in round gobies (Apollonia melanostoma, formerly Neogobius melanostomus), a recent invader in the Great Lakes. Dark morph males exhibited secondary sexual characteristics, were larger and had higher plasma 11-ketotestosterone concentrations than light morphs, while light morph males invested more in ejaculates (both testes mass and sperm density). Both male morphs had enlarged urogenital papillae, but papillae were relatively longer in light morph males. Sperm tail length did not differ between morphs, and sperm from dark morphs swam faster than sperm from light morphs. Our data strongly argue for the presence of alternative tactics in round gobies, support some predictions from sperm competition theory and align with empirical observations in other taxa. For species of concern like the invasive round goby, it is critical to consider such evidence of alternative male mating tactics when constructing population growth models and assessment of invasion success and impacts.
\end{abstract}

(c) 2009 Elsevier Inc. All rights reserved.

\section{Introduction}

Male alternative reproductive tactics (MARTs) emerge when competition for mating opportunities is fierce and the potential exists for some males to reduce fitness costs by exploiting the reproductive investment of other males (Oliveira et al., 2008). Among fishes, MARTs are particularly common and are taxonomically widespread, because external fertilization is prevalent (allowing simultaneous sperm release from several males), somatic growth is indeterminate (creating large variance in body size and resource sequestering abilities among males), and paternal care is common (providing strong fitness pay-offs to male sneakers that avoid the costs of courtship and parental care; Oliveira, 2006; Taborsky, 1998). The aim of this study was to comprehensively examine the possibility of MARTs in the round

\footnotetext{
* Corresponding author

E-mail addresses: marentjr@mcmaster.ca (J.R. Marentette), jfitzpat@cyllene.uwa.edu.au (J.L. Fitzpatrick), bergerrg@mcmaster.ca (R.G. Berger), sigal@mcmaster.ca (S. Balshine).

${ }_{1}^{1}$ Tel.: +61864884511.

2 Tel.: +1905 $5259140 \times 26037$

${ }^{3}$ Tel.: +1905 525 9140x23024.
}

goby (Apollonia melanostoma, formerly Neogobius melanostomus), a recent prolific Ponto-Caspian invader of the Laurentian Great Lakes and aquatic biotas in northeastern Europe (Corkum et al., 2004).

Although the round goby poses a serious threat to native fauna ecology and conservation (e.g., Jude et al., 1995), its reproductive habits are still not fully understood. Breeding fish are difficult to observe in the wild (Wickett and Corkum, 1998) and spawning is rarely achieved under laboratory conditions (L.D. Corkum, University of Windsor, personal communication; J.R. Marentette, personal observation), complicating efforts to study reproduction directly. However, understanding round goby reproduction is critically important in terms of predicting the ecological impacts of this invasive species. Round gobies belong to the speciose teleost family Gobiidae that contains several species with male alternative reproductive tactics, including the common goby, Pomatoschistus microps (Magnhagen, 1992), black goby, Gobius niger (Mazzoldi and Rasotto, 2002), and the sand goby, Pomatoschistus minutus (Svensson, 2004). Sneaking behaviour has been observed in the round goby (C. Murphy, University of Alberta, personal communication) and has been reported to occur in a number of publications (Corkum et al., 1998; MacInnis, 1997; Marentette and Corkum, 2008). However, these 
reports are based on limited laboratory behavioural observations and a few morphological observations.

To investigate the claim of MARTs in round gobies, we examined the external morphology, internal anatomy, endocrinology and sperm characteristics of male round gobies from Lake Ontario in light of sperm competition theory and current knowledge of MARTs in vertebrates. In general, male tactics can be divided into two categories. Parental males, sometimes called conventional, type I or bourgeois males, are large, invest more in growth than in reproduction, defend territories, court females, exhibit secondary sexual characteristics, and have elevated androgen concentrations (Oliveira et al., 2008). In contrast, sneaker, type II or parasitic males are smaller, invest in reproduction at the cost of growth, and lack secondary sexual characteristics. Rather than court females, these sneaker males add their ejaculate surreptitiously to spawnings in progress by stealth, speed, or by imitating females (Oliveira et al., 2008). Males will be subject to asymmetric risks of sperm competition, the competition between sperm from rival males to fertilize a female's ova (Parker, 1970), depending on the reproductive tactic employed. Because parental males are sometimes able to sequester mates and drive off competitors including sneakers, they experience a relatively lower risk of sperm competition. In contrast, sneaker males experience sperm competition during every mating, as by definition they only release sperm in the presence of a parental male. Thus, in order to overcome their disadvantage, sneaker males are expected to invest more in sperm number than parental males (Parker and Ball, 2005). Sperm competition is also thought to lead to sperm with longer flagella that swim faster (Ball and Parker, 1996). Sperm tail length is associated with sperm swimming speed (Fitzpatrick et al., 2009) and, in external fertilizers, sperm swimming speed predicts fertilization success in competitive matings (Gage et al., 2004).

We predicted that if two alternative reproductive tactics exist in round gobies, one morph (presumably the parental male morph) would be larger than the other morph (the sneaker male morph). Since secondary male sexual traits are associated with high levels of androgens, we predicted that plasma concentrations of 11-ketotestosterone (11-KT), the primary fish androgen, would be higher in parental males than in sneaker males (Oliveira et al. 2008). We also predicted that parental males would invest comparatively less in testes mass than sneaker males, and that sneaker males, which encounter higher levels of sperm competition would produce more sperm that have longer flagella and swim faster than the sperm of parental males (Ball and Parker, 1996; Parker and Ball, 2005).

\section{Methods}

Round gobies $(n=1295)$ were collected in minnow traps or by electrofishing from Hamilton Harbour between June 26 to August 23,
2006, and May 16 to August 29, 2007, and from nearby Jordan Harbour in Lake Ontario on July 21, 2006. Traps baited with $25 \mathrm{~g}$ frozen corn were set in $<1 \mathrm{~m}$ of water every 2 weeks, and were collected after $24 \mathrm{~h}$. Fish were then transported to McMaster University and maintained in aerated laboratory aquaria before processing.

The sexes were differentiated by the shape of the urogenital papilla, which is broad and square in females, but narrow and pointed in males (Miller, 1984). Fish that did not possess identifiable papillae were classified as juveniles, and all males with small flat papillae were classified as non-reproductive (non-spawning males). Dissections revealed the size and maturity of testes and confirmed this male classification scheme. All males with erect papillae were shown by dissection to have mature testes (see measurements below). Males with erect papillae that had dark to black bodies were classified as dark morph males and we considered these to be putative parental males, since nest-holding round goby males have been reported to have black nuptial coloration (Corkum et al., 1998). Males with erect urogenital papillae that had light, mottled juvenile or female-shaped bodies (see below) were then classified as light morph males and putative sneakers. Using this classification scheme, of the 752 adult males captured, 144 were classified as dark morph and 151 as light morph males, with the remainder classed as non-reproductive males.

Fish were all measured for total length (TL), head width (taken across the posterior orbital edge), and urogenital papilla length (anterior insertion to posterior tip), all to $0.1 \mathrm{~mm}$ (Fig. 1). Total body mass and the mass of the gonads were measured to $0.001 \mathrm{~g}$. The gonads of male round gobies have two sets of paired organs: 1 ) testes and 2) accessory structures also called seminal vesicles or sperm-duct glands (Miller, 1984). The function of these accessory glands has been linked to sperm storage, production of mucus for laying sperm trails (lines of sperm embedded in mucus, laid on nest surfaces), and pheromone production (Jasra et al., 2007; Mazzoldi et al., 2005; Fig. 1). Hence the mass of testes and accessory glands were recorded separately. Based on these measures we calculated a somatic mass as the total body mass - total gonad mass (testes and accessory glands combined). We also calculated a papilla index or PI (papilla length $/ \mathrm{TL} \times 100 \%$ ), testicular somatic index or TSI (testes mass / somatic mass $\times 100 \%$ ), and accessory gland somatic index or AGSI (accessory gland mass / somatic mass $\times 100 \%$ ).

Blood samples were collected in heparinized $10 \mu \mathrm{L}$ micro-capillary tubes from a representative sample of 14 dark morph and 14 light morph males by caudal severance $0-2$ days after capture, and spun at 14,500 RPM for $10 \mathrm{~min}$. Collection day was random, did not vary between the two morphs and had no correlation with 11-KT concentrations for either morph (Spearman rho, $p>0.2$ for both dark and light morphs). The plasma was then removed and frozen at $-80^{\circ} \mathrm{C}$. Steroids were extracted from the samples by shaking $5 \mu \mathrm{L}$ of plasma with $5 \mathrm{ml}$ of diethyl ether. After freezing the aqueous phase in

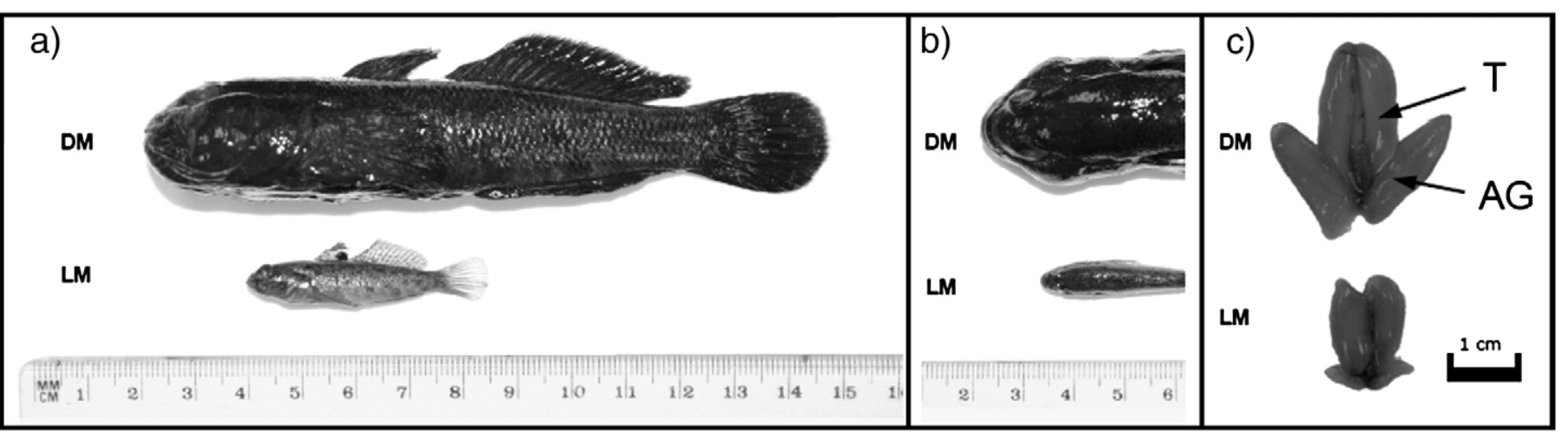

Fig. 1. (a) External morphology (lateral view) of a dark morph male (DM) and a light morph male (LM) showing differences in colour and body size. (b) Anterior dorsal view of a dark morph male (DM) and a light morph male (LM) showing differences in head width. (c) Dissected testes of dark morph males (range 96.9-131.3 mm TL, top row) and light morph males (range 45.0-70.6 mm TL, bottom row). This photo shows the relative investment in lobes of the testes ( $\mathrm{T}$ ) versus accessory glands (AG). A scale appears below (in $\mathrm{cm}$ ). 
an acetone/dry ice bath, the organic phase was decanted and dried. The dry extracts were resolubilized in $500 \mu \mathrm{L}$ EIA buffer and frozen at $-20{ }^{\circ} \mathrm{C}$ to be assayed for $11-\mathrm{KT}$ at a later date. On the day of the assay procedure, the parent solution was thawed and further diluted with EIA buffer to generate a 1:200 working solution. 11-KT levels were assessed using a commercially available Enzyme Immunosorbant Assay kit (Cayman Chemical Inc.). Standards and samples were run in duplicate on a single plate. Plates were read using a microplate reader with a single filter at $405 \mathrm{~nm}$ (Bio-Tek Instruments Inc., model Elx 808). The percent bound for each sample was calculated using the maximum bound value as reference, and were excluded from analysis if their values fell outside $20-80 \%$ bound.

Milt was collected from the dabbed dry papillae of a representative sample of 14 dark morph and 21 light morph males in 2007 following submersion in ice water. This process typically induced ejaculation, and further milt was produced by gentle abdominal massaging. Urine was expelled by abdominal massage before milt samples were taken to avoid contamination or activation of sperm. We also measured the spermatocrit, or the proportion of solid packed material in semen, after centrifugation. Spermatocrit values are used as indicators of spermatozoa density and correspond well to density measures obtained from manual haemocytometer-based sperm counts (Tvedt et al., 2001). Spermatocrit was measured by filling a microhematocrit capillary tube with milt (sperm and seminal plasma) and centrifuging this tube for $10 \mathrm{~min}$ in a microhematocrit centrifuge. This procedure causes sperm cells to pack down in the capillary tube, forming an opaque layer below a clear layer of seminal fluid. The spermatocrit was recorded as the percent of total volume formed by the sperm cells (Liljedal et al., 1999). Sperm smears (5 $\mu \mathrm{L}$ of milt or testicular fluid diluted in $200 \mu \mathrm{L}$ distilled water) were collected from 21 dark morph and 11 light morph males in 2006 and 2007. Ten clearly visible spermatozoa were photographed at $400 \times$ magnification under phase contrast from each male (Prosilica EC-650 camera, software Astro IIDC v3.02.01), and the length ( $\mu \mathrm{m})$ of each flagellum was measured, tip to midpoint of head, with Image] $1.37 \mathrm{v}$ (Wayne Rasband, National Institutes of Health, U.S.A., available at http://rsb.info.nih.gov/ij) (Fitzpatrick et al., 2009). A mean sperm length was then computed for each male.

Video recordings of sperm from 10 dark and 11 light morph males caught in 2007 were captured at $200 \times$ magnification, under phase contrast, at 240 fps using a Prosilica EC-650 camera. Sperm were collected from either milt or dissected testes and activated by $200 \mu \mathrm{L}$ of filtered water from Hamilton Harbour. Sperm velocity for each male was measured in one second intervals as the VAP (smoothed path velocity, $\mu \mathrm{m} / \mathrm{s}$ ), using a CEROS video analysis program (Hamilton-Thorne Research, Beverly, Maine, U.S.A.) at 20, $30,45,60,90,120,180,240,360,480$, and 600 s. Only spermatozoa whose forward movement was traced for at least $0.33 \mathrm{~s}$ and samples with at least five swimming sperm per time period were analyzed.

\section{Statistical analyses}

All analyses were performed using JMP 5.0.1a (SAS Institute, Inc., 2002). Despite their common use to measure reproductive investment, ratio indices such as GSI, TSI or AGSI have recently come under scrutiny (Tomkins and Simmons, 2002) because such measures assume isometry of body proportions in animals of varying size. As the assumption of isometry is rarely met, using these indices may lead to incorrect conclusions about the differences between groups. Hence we used ANCOVA models as proposed by Tomkins and Simmons (2002) to account for allometry among individuals and accurately detect differences in allometry between groups. However, as the use of the ratio indices is extremely common in studies of fish reproduction, and the interpretation of ANCOVA models can be complicated by significant covariate-main effect interaction terms, we employed both methods (after Neff et al., 2003), to examine differences between parental and sneaker males and facilitate comparisons with published studies.

Body measures were log-transformed and testes mass, accessory gland mass, papilla length and head width data were fitted to an ANCOVA model, with male morph as a factor and either the logarithm of somatic mass or TL as the covariate. Where covariatemorph interaction terms were not significant $(p>0.05)$, they were removed from the model (Engqvist, 2005) and only the subsequent model $F$ values were reported. Indices (TSI, AGSI, PI), concentrations of 11-KT, sperm tail length, and spermatocrit values were analyzed by Student's $t$-test (arcsine- or log-transformed if necessary) or by the normal approximation to the Wilcoxon rank sum nonparametric test where normalization could not be achieved. Sperm velocity was examined using a repeated-measures ANOVA as the log-transformed median VAP with time and male morph as fixed factors. Means, standard errors, medians and ranges for all measurements are provided in Table 1 .

\section{Results}

\section{External body morphology}

Dark morph males were larger $\left(t_{293}=19.8, p<0.0001\right)$ and heavier $\left(t_{293}=19.3, p<0.0001\right.$, Table 1, Fig. 1a) than light morph males. Dark morph males had wider heads compared with light morphs (ANCOVA, whole model $F_{2,292}=1865, p<0.0001$; male morph $F_{1,292}=54.3$, $p<0.0001$; Fig. 1b).

Table 1

Summary statistics for body measurements of dark and light morph males.

\begin{tabular}{|c|c|c|c|c|}
\hline & \multicolumn{2}{|c|}{ Dark morph males } & \multicolumn{2}{|c|}{ Light morph males } \\
\hline & Mean (SE) & Median (range) & $\overline{\text { Mean (SE) }}$ & Median (range) \\
\hline Total length $(\mathrm{mm})^{\mathrm{a}}$ & $98.9(1.6)$ & $96.3(61.5-161.0)$ & $65.5(1.2)$ & $65.5(43.5-90.3)$ \\
\hline Total mass $(\mathrm{g})^{\mathrm{a}}$ & $14.23(0.78)$ & $11.26(2.97-56.02)$ & $3.94(0.16)$ & $3.67(1.07-10.14)$ \\
\hline TSI $(\%)^{\mathrm{a}}$ & $1.60(0.06)$ & $1.46(0.26-5.64)$ & $4.22(0.18)$ & $4.22(0.60-9.59)$ \\
\hline $\operatorname{AGSI}(\%)^{\mathrm{a}}$ & $0.70(0.03)$ & $0.64(0.00-2.07)$ & $0.39(0.03)$ & $0.34(0.00-1.20)$ \\
\hline PI $(\%)^{\mathrm{a}}$ & $5.17(0.07)$ & $5.09(3.39-7.96)$ & $6.71(0.12)$ & $6.59(3.66-11.26)$ \\
\hline $11-\mathrm{KT}(\mathrm{ng} / \mathrm{mL})^{\mathrm{b}}$ & $3.29(0.60)$ & $1.81(0.79-10.65)$ & $0.87(0.60)$ & $0.56(0.22-2.31)$ \\
\hline Spermatocrit (\%) ${ }^{\mathrm{C}}$ & $56.4(5.2)$ & $48.3(38.5-98.8)$ & $88.2(2.2)$ & $92.3(62.5-100)$ \\
\hline Sperm tail length $(\mu \mathrm{m})^{\mathrm{d}}$ & $30.28(0.38)$ & $30.35(27.82-33.17)$ & $30.15(0.52)$ & $30.16(26.85-33.22)$ \\
\hline
\end{tabular}

$\mathrm{TSI}=$ testicular somatic index. AGSI = accessory gland somatic index. PI = papilla index. $11-\mathrm{KT}=11$-ketotestosterone. Indices are expressed as the percentage of somatic mass (TSI, AGSI), total length (PI) or ejaculate volume (spermatocrit).

a $n=144$ dark, 151 light morph males.

$n=14$ dark, 14 light morph males.

$n=14$ dark, 21 light morph males.

d $n=21$ dark, 11 light males. 
Gonads and urogenital papillae

Light morph males invested nearly three times as much as dark morphs in testes (median score was 2.8 times more massive; $Z=$ $-10.62, p<0.0001$, Fig. 2a), while dark morph males invested twice as much as light morphs in accessory glands (median score was 2.0 times more massive; $Z=8.36, p<0.0001$, Figs. $1 \mathrm{c}$ and $2 \mathrm{c}$ ). Light morph males had relatively longer urogenital papillae $\left(t_{268}=11.1\right.$, $p<0.0001$, Fig. 2e). ANCOVA models confirmed that light males had relatively larger testes (whole model $F_{3,289}=79.1$; male morph $F_{1,289}=33.4, p<0.0001$, Fig. 2 b) and that dark morph males invested significantly more than light morphs in accessory gland tissue (whole model $F_{2,274}=361.7$; male morph $F_{1,274}=28.3, p<0.0001$, Fig. 2d). No morph difference in papilla length was observed when an ANCOVA model was applied (whole model $F_{3,266}=53.6$; male
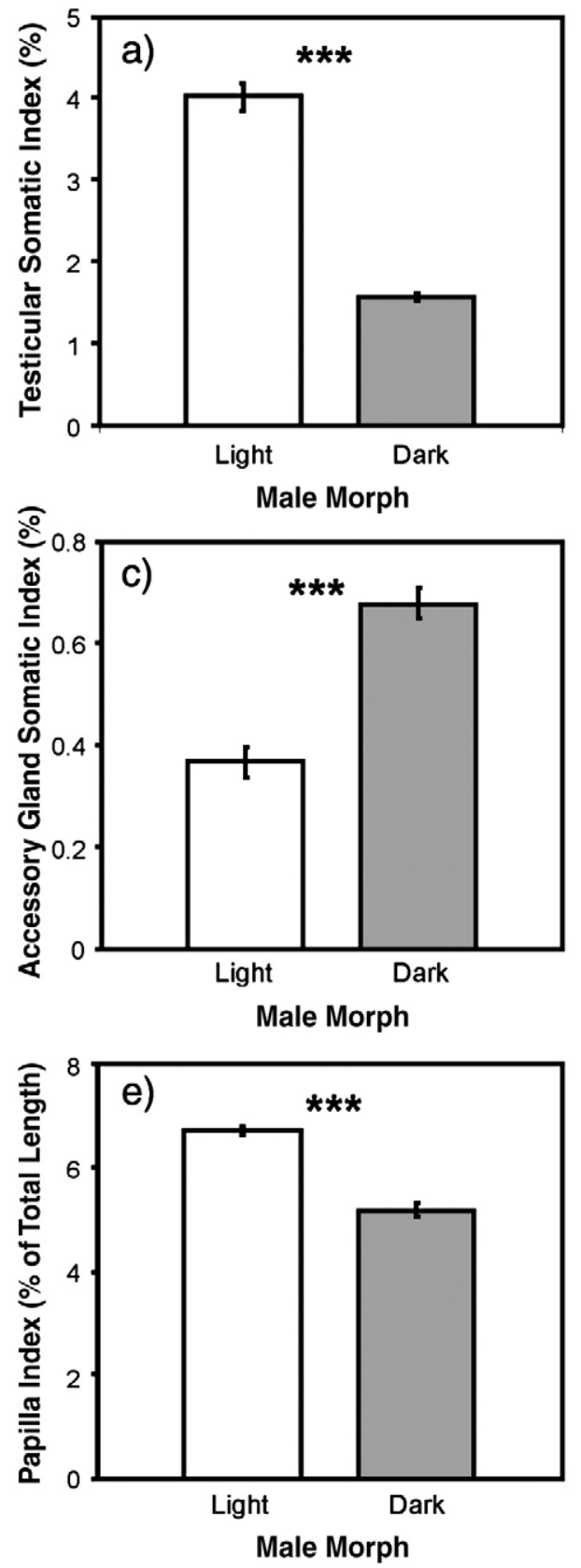

morph $F_{1,266}=1.5, p=0.23$, Fig. 2f) but the significant interaction between the covariate (log somatic mass or $\log \mathrm{TL}$ ) and the main effect of male morph made it difficult to interpret main effects (covariate-morph interaction terms were $F_{1,289}=15.6, p<0.0001$ for testes mass and $F_{1,266}=10.8, p=0.0012$ for papilla length). Adding and subtracting $1 \mathrm{SD}$ from the covariate of one male group (a method suggested by Tomkins and Simmons, 2002 to overcome significant covariate interaction terms) did not yield the same male morph effect.

\section{Hormones and sperm}

Dark morph males had significantly higher concentrations of plasma 11-KT than light morph males $\left(t_{26}=4.2, p=0.0003\right.$, Fig. 3 ). Spearman rho correlations showed that $11-\mathrm{KT}$ levels did not vary
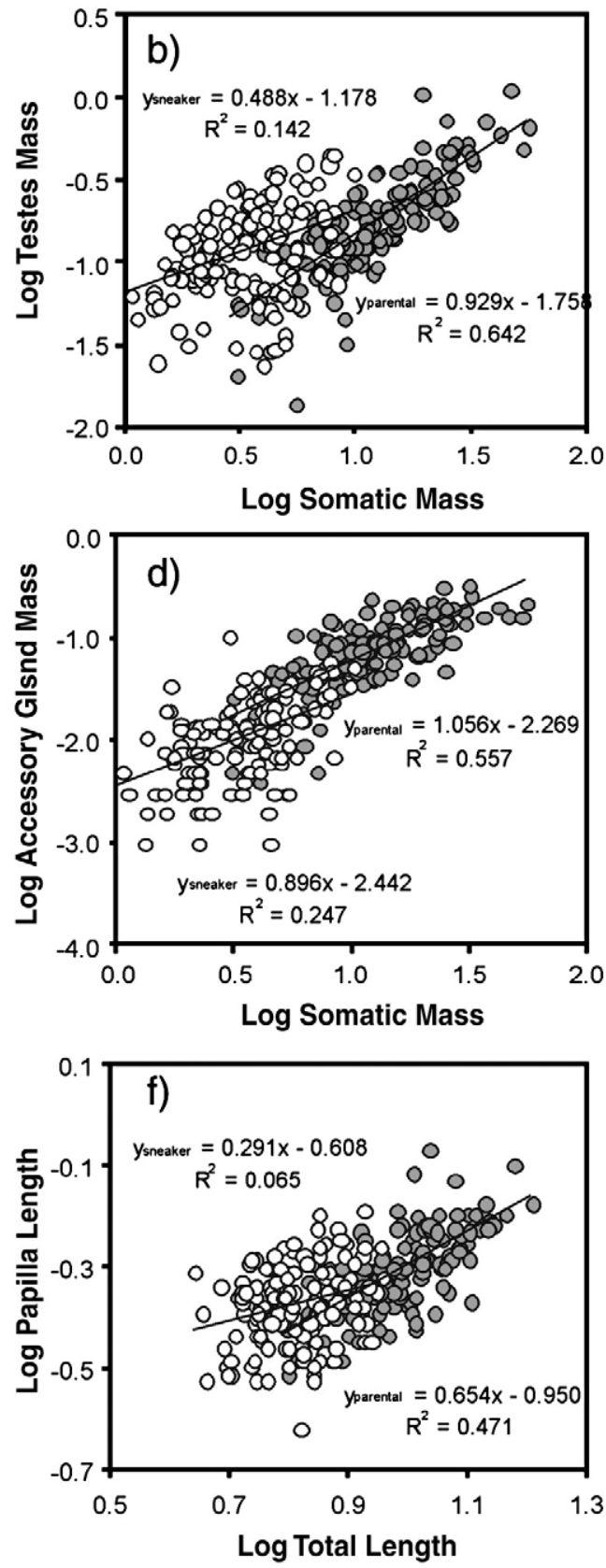

Fig. 2. Measures of reproductive investment in male round goby. Gray bars or circles $=$ dark morph males. White bars or circles $=$ light morph males. Asterisks $(* * *)$ indicate significant differences between morphs at $p<0.0001$. (a) Mean \pm SE of the testicular somatic index. (b) Plot of log testes mass versus log of somatic mass. (c) Mean \pm SE of the accessory gland somatic index. (d) Plot of log accessory gland mass versus log of somatic mass. (e) Mean \pm SE of the papilla index. (f) Plot of log papilla length versus log of total length. 


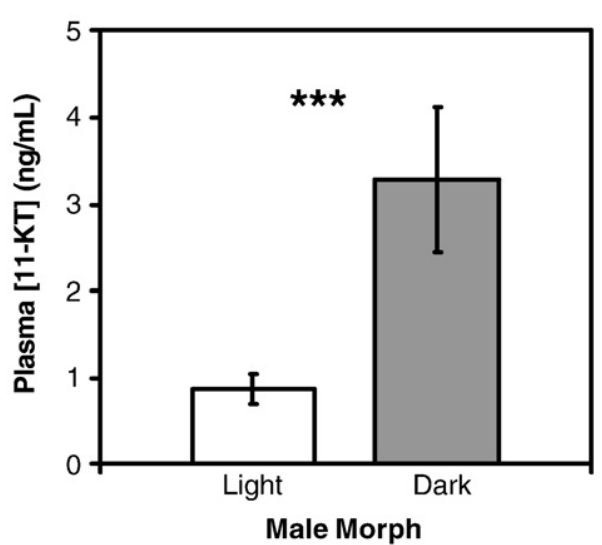

Fig. 3. Differences in mean $\pm S E$ plasma concentrations $(\mathrm{ng} / \mathrm{mL})$ of the primary fish androgen 11-ketotestosterone for dark morph (gray bar) and light morph (white bar) males.

within a male morph with the number of days spent in the laboratory prior to testing $\left(R_{\mathrm{s}}=0.35\right.$ and $-0.06, p>0.2$ for both dark and light morphs respectively). Sperm tail length did not vary between dark and light morph males $\left(t_{30}=0.2, p=0.84\right)$. However, light morph males had a higher density of sperm in their ejaculates than did dark morphs (median score was 1.89 times greater; $Z=$ $-3.9, p<0.0001$, Fig. 4a). Sperm velocity decreased with time $\left(F_{10,89}=14.5, p<0.0001\right)$. However, a significant interaction between time and male morph indicated that the rate of decline in sperm velocity was dependent on male morph $\left(F_{10,89}=2.3, p=0.2\right)$. Sperm velocity did not differ significantly between morphs alone $\left(F_{1,19}=0.2, p=0.67\right.$; Fig. 4 b). Dark morph sperm swam faster than light morph sperm only at 180 and $240 \mathrm{~s}$ post-activation (Tukey, $p<0.05$, Fig. 4b).

\section{Discussion}

The multiple lines of evidence pursued in this study, including data on external morphology, reproductive investment, endocrinology and sperm characteristics, converge to corroborate the hypothesis that the round goby possesses two morphologically and physiologically distinct male morphs that we predict correspond to alternative male reproductive tactics. The dark morph has traits corresponding to a parental male tactic, and the light morph has traits corresponding to a sneaker male tactic. One morph, the dark morph, was physically larger, invested more in accessory glands and had higher concentrations of plasma 11-KT. These traits are seen in parental males. The other morph, the light morph, invested more in testes mass and had a greater volume of sperm in their ejaculate than did dark morphs. These traits are seen in sneaker males. These results are consistent with the predictions of sperm competition theory (Parker, 1970) and empirical observations in many species (Montgomerie and Fitzpatrick, 2009; Oliveira et al., 2008). Although a number of different fish studies have confirmed that parental males will have higher levels of 11-KT (Oliveira, 2006), to our knowledge this is the first demonstration of this pattern in Gobiidae, one of the most speciose of teleost fish families (at least 1875 species, in more than 200 genera; Nelson, 2006).

Our results based on ratio indices (assuming isometry), and those based on ANCOVA models (assuming allometry), both support the finding of greater testicular investment in sneakers and greater accessory gland investment in parentals. A relatively longer urogenital papilla in sneaker males compared to parental males has not, to our knowledge, been previously reported in gobiids or for any other fish species. In the Azorean rock-pool blenny Parablennius sanguinolentus parvicornis, it is the bourgeois or parental males that exhibit longer and wider papillae than the satellite morph (Oliveira et al.,
2001). It is possible that a relatively longer papilla allows sneaker males to fertilize eggs more efficiently or from a greater distance than if they had a papilla proportionately equal in length to parental males. There may be a threshold papilla length required for fertilization success, but the non-significant effect of male morph in the ANCOVA model, complicated by a significant morph-covariate interaction, suggests that papilla differences between tactics need to be studied further and interpreted carefully.

Among fishes especially, sperm competition is expected to have selected for longer sperm and/or faster swimming speed because the first sperm that swims down the micropyle on the egg fertilizes that egg (Yanagimachi et al., 1992). Yet, at most time periods we found no differences in sperm length or sperm swimming speed between morphs. While Burness et al. (2004) reported that sneaker males had longer sperm, in accordance with theoretical predictions, in fact the majority of studies that have examined sperm morphology of males exhibiting alternative reproductive tactics have failed to find differences in sperm length within species (Fitzpatrick et al., 2007; Gage et al., 1995; Leach and Montgomerie, 2000). Thus the selective forces acting on sperm morphology and function in species with alternative reproductive tactics remain unresolved. An exploration of differences in sperm energetics between tactics may help resolve these issues (Burness et al., 2005; Fitzpatrick et al., 2007; Fitzpatrick et al., 2009).

While the predicted pattern of faster sperm in light morph (putative sneaker) males was not found in our study, there remains the distinct possibility that in the earlier time periods (i.e., from 0 to $20 \mathrm{~s}$ post-activation) not measured in this work, round goby light morph sperm does indeed swim at greater velocities. Burness et al.
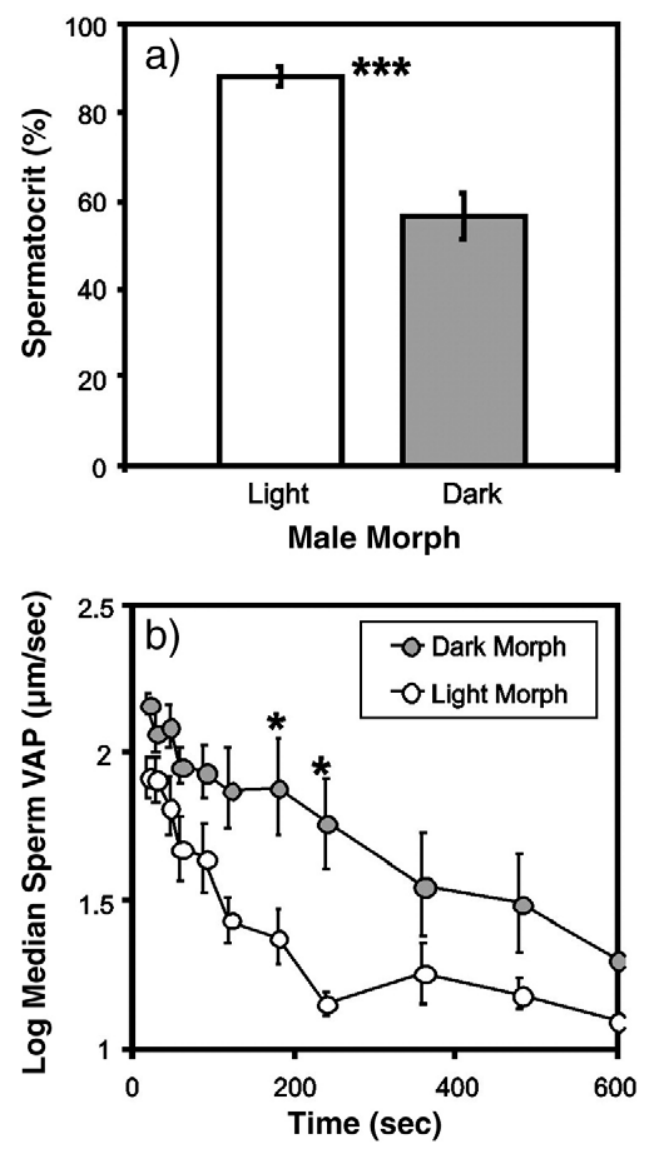

Fig. 4. (a) Differences in spermatocrit for dark morph (gray bar) and light morph (white bar) males. (b) Changes in median VAP (smoothed path sperm velocity) with time in dark morph (gray circles) and light morph (white circles) males. Asterisks $\left(^{*}\right)$ indicate differences between morphs at $p<0.05$. 
(2004) showed that sperm from bluegill sneakers swam faster than parental males but that it did so only at time periods $<20 \mathrm{~s}$. In fact, sperm from bluegill parental males swam faster than sneaker males at later time periods, consistent with our results. The initially faster sperm in bluegill sneakers followed by a rapid decline in swimming speed was interpreted by Burness et al. (2004) as a trade-off between speed and longevity in ejaculates. A similar trade-off may be present in round gobies. Interestingly, in the black goby, sneaker sperm was faster than that of parental males both at 0 and 30 min post activation but in the grass goby sperm velocity did not differ between tactics (Locatello et al., 2007). Similarly, round goby light morphs may invest solely in elevated sperm production - a possibility supported by the higher density of sperm per unit ejaculate obtained from light morphs. This would suggest that in competitive spawnings, round goby light morph males might rely on sperm number rather than sperm quality to secure fertilizations. Alternatively, parental male sperm laid down in sperm trails (known to be produced by gobiids; Miller, 1984) well in advance of fertilization may be selected for prolonged swimming capacity compared to sperm of sneaker males, which may release ejaculates only in the presence of a spawning female. Further examination of sperm and ejaculate characteristics in round gobies is needed, with particular emphasis on early phases of activation, to answer these questions.

In this study we provide evidence for the presence of multiple male morphs in round gobies and argue that these morphs represent alternative male tactics. Yet, key pieces of evidence remain to be resolved before alternative male reproductive tactics can be conclusively identified in round gobies. The most urgent of these is rigorous behavioural confirmation of tactics and establishing that light morphs engage in parasitic spawnings. If light males are indeed sneakers then it would be valuable to know if they rely on stealth and speed, or act as a female mimic to gain reproductive success. Further, although not definitive, evidence of multiple paternity from egg clutches collected from wild nests could indicate the presence of any cuckoldry.

The round goby and its reproductive habits are of interest not only because of the known impacts of this species on native fauna, but also because there has been a call to stem further invasions through exploitation of chemical (Corkum, 2004) or auditory (D. Higgs, University of Windsor, personal communication) reproductive signaling. The presence of alternative reproductive tactics in round gobies is likely to have profound implications for population growth via annual recruitment of juveniles. This recruitment will be influenced by the number and quality of males providing care - which in turn will depend on the availability of nesting sites and the degree of malemale competition for these nests.

The frequency of light to dark morph males in our study was approximately $1: 1$. We predict that the frequency of light to dark morph males will reflect the various stages of an invasion. For example, when a new habitat is being initially colonized, male-male competition should be low as all males will be able to access nest sites. Hence, alternative male reproductive tactics will not be favoured. However, as the population grows and becomes more dense, nest sites may become limited and male-male competition is expected to increase, favouring the evolution of alternative male tactics, and sneakers (as light morphs) would be expected to be more common. Iguchi et al. (2004) reported evidence for an escalation of male-male competition, in invasive versus native populations of smallmouth bass (Micropterus dolomieu), possibly due to heightened competition for nest sites in the new habitats. However, when Jones et al. (2001) examined sneaking rates in two sand goby populations, one with high and one with low nest densities, they found no difference in rates of sneaking. The degree of sexual selection itself rather than nest density per se (as one contributor to sexual selection) may be the factor that will select for increased alternative male reproductive behaviour. In addition, invasive populations of round gobies in North America reach sexual maturity faster, have shorter lifespans, and are smaller than round gobies from native populations (Macinnis and Corkum, 2000). Life history trait modulation may have facilitated round goby invasion speed and range expansion as invasive populations apparently cycle more quickly. Having a relatively plastic life history, which may include the presence of alternative male reproductive tactics, may arm a species with the ability to adaptively respond to sudden changes in environmental conditions or to novel environments and hence this flexibility may predispose round gobies to successful invasions (Balázová-L'avrincíková and Kovác, 2007).

\section{Acknowledgments}

The authors would like to thank S. Marsh-Rollo, C. Gross, A. Schermel, A. Stosic, D. Re and K. Gooderham for their help in fish and data collection, L. Corkum for comments on the manuscript and D. deCatanzaro and R. Montgomerie for the use of their facilities. All studies were approved by the McMaster University Animal Research Ethics Board (AREB) and comply with the current laws of Canada (AUPs \# 03-09-54 and 06-10-61). This research was supported by the Department of Fisheries and Oceans Canada, an Ontario Graduate Scholarship (JRM) and a Natural Sciences and Engineering Research Council of Canada Discovery Grant (SB).

\section{References}

Balázová-L'avrincíková, M., Kovác, V., 2007. Epigenetic context in the life history traits of the round goby, Neogobius melanostomus. In: Gherardi, F. (Ed.), Biological invaders in inland waters: Profiles, distributions and threats. Springer, New York, pp. 275-287.

Ball, M.A., Parker, G.A., 1996. Sperm competition games: external fertilization and "adaptive" infertility. J. Theoret. Biol. 180, 141-150.

Burness, G., Casselman, S.J., Schulte-Hostedde, A.I., Moyes, C.D., Montgomerie, R., 2004 Sperm swimming speed and energetics vary with competition risk in bluegill (Lepomis macrochirus). Behav. Ecol. Sociobiol. 56, 65-70.

Burness, G., Moyes, C.D., Montgomerie, R., 2005. Motility, ATP levels and metabolic enzyme activity of sperm from bluegill (Lepomis macrochirus). Comp. Biochem. Physiol., A Mol. Integr. Physiol. 140, 11-17.

Corkum, L.D., 2004. Pheromone signaling in conservation. Aquat. Conserv. Mar. Freshw. Ecosyst. 14, 327-331.

Corkum, L.D., MacInnis, A.J., Wickett, R.G., 1998. Reproductive habits of round gobies. Great Lakes Res. Rev. 3, 13-20.

Corkum, L.D., Sapota, M.R., Skora, K.E., 2004. The round goby, Neogobius melanostomus, a fish invader on both sides of the Atlantic Ocean. Biol. Invasions 6, 173-181.

Engqvist, L., 2005. The mistreatment of covariate interaction terms in linear model analyses of behavioural and evolutionary ecology studies. Anim. Behav. 70, 967-971.

Fitzpatrick, J.L., Desjardins, J.K., Milligan, N., Montgomerie, R., Balshine, S., 2007. Reproductive-tactic-specific variation in sperm swimming speeds in a shellbrooding cichlid. Biol. Reprod. 77, 280-284.

Fitzpatrick, J.L., Montgomerie, R., Desjardins, J.K., Stiver, K.A., Kolm, N., Balshine, S., 2009. Female promiscuity promotes the evolution of faster sperm in cichlid fishes. Proc. Nat. Acad. Sci. 106, 1128-1132.

Gage, M.J., Stockley, P., Parker, G.A., 1995. Effects of alternative mating strategies on characteristics of sperm production in the Atlantic salmon (Salmo salar): theoretical and empirical investigations. Proc. R. Soc. Lond., B Biol. Sci. 350, 391-399.

Gage, M.J., MacFarlane, C.P., Yeates, S., Ward, R.G., Searle, J.B., Parker, G.A., 2004. Spermatozoal traits and sperm competition in Atlantic salmon: relative sperm velocity is the primary determinant of fertilization success. Curr. Biol. 1, 44-47.

Iguchi, K., Yodo, T., Matsubara, N., 2004. Spawning and brood defense of smallmouth bass under the process of invasion into a novel habitat. Env. Biol. Fish. 70, 219-225.

Jasra, S.K., Arbuckle, W.J., Corkum, L.D., Li, W., Scott, A.P., Zielinski, B., 2007. The seminal vesicle synthesizes steroids in the round goby Neogobius melanostomus. Comp. Biochem. Physiol., A Mol. Integr. Physiol. 148, 117-123.

Jones, A.G., Walker, D., Lindstrom, K., Kvarnemo, C., Avise, J.C., 2001. Surprising similarity of sneaking rates and genetic mating patterns in two populations of sand goby experiencing disparate sexual selection regimes. Mol. Ecol. 10, 461-469.

Jude, D.J., Janssen, J., Crawford, G., 1995. Ecology, distribution and impact of the newly introduced round and tubenose gobies on the biota of the St. Clair and Detroit Rivers. In: Munawar, M., Edsal, T., Leach, J. (Eds.), The Lake Huron Ecosystem: Ecology, Fisheries and Management. Ecovision World Monograph Series. SPB Academic Publishing, Amsterdam, pp. 447-460.

Leach, B., Montgomerie, R., 2000. Sperm characteristics associated with different male reproductive tactics in bluegills (Lepomis macrochirus). Behav. Ecol. Sociobiol. 49, 31-37.

Liljedal, S., Folstad, I., Skarstein, F., 1999. Secondary sex traits, parasites, immunity and ejaculate quality in the Arctic charr. Proc. R. Soc. Lond., B Biol. Sci. 266, 1893-1898. 
Locatello, L., Pilastro, A., Deana, R., Zarpellon, A., Rasotto, M.B., 2007. Variation pattern of sperm quality traits in two gobies with alternative mating tactics. Funct. Ecol. 21 975-981.

MacInnis, A.J., 1997. Aspects of the life history of the round goby, Neogobius melanostomus (Perciformes: Gobiidae), in the Detroit River. M.Sc. thesis, University of Windsor, Windsor, Ontario, Canada.

MacInnis, A.J., Corkum, L.D., 2000. Age and growth of the round goby Neogobius melanostomus in the Upper Detroit River. Trans. Am. Fish. Soc. 129, 852-858.

Magnhagen, C., 1992. Alternative reproductive behaviour in the common goby Pomatoschistus microps: an ontogenetic gradient? Anim. Behav. 44, 182-184.

Marentette, J.R., Corkum, L.D., 2008. Does the reproductive status of male round gobies (Neogobius melanostomus) influence their response to conspecific odours? Env. Biol. Fish. 81, 447-455.

Mazzoldi, C., Rasotto, M.B., 2002. Alternative male mating tactics in Gobius niger. J. Fish Biol. 61, 157-172.

Mazzoldi, C., Petersen, C.W., Rasotto, M.B., 2005. The influence of mating system on seminal vesicle variability among gobies (Teleostei: Gobiidae). J. Zool. Syst. Evol. Res. 43, 307-314.

Miller, P.J., 1984. The tokology of gobioid fishes. In: Potts, G.W., Wootton, R.J. (Eds.), Fish reproduction: strategies and tactics. Wootton Academic Press, London, pp. 119-153.

Montgomerie, R., Fitzpatrick, J.L., 2009. Testes, sperm, and sperm competition In: Jamieson, B.G.M. (Ed.), Reproductive Biology and Phylogeny of Fishes (Agnathans and Bony Fishes). Science Publishers, Enfield, New Hampshire, pp. $1-53$.

Neff, B.D., Fu, P., Gross, M.R., 2003. Sperm investment and alternative mating tactics in bluegill sunfish (Lepomis macrochirus). Behav. Ecol. 14, 634-641.

Nelson, J.S., 2006. Fishes of the World, 4th Ed. John Wiley and Sons, Inc, Hoboken, New Jersey.
Oliveira, R.F., 2006. Neuroendocrine mechanisms of alternative reproductive tactics in fish. In: Sloman, K.A., Wilson, R.W., Balshine, S. (Eds.), Behaviour and Physiology of Fish. Elsevier Academic Press, San Diego, pp. 297-357.

Oliveira, R.F., Carneiro, L.A., Canario, A.V.M., Grober, M.S., 2001. Effects of androgens on social behaviour and morphology of alternative reproductive males of the Azorean rock-pool blenny. Horm. Behav. 39, 157-166.

Oliveira, R.F., Taborsky, M., Brockmann, H.J., 2008. Alternative Reproductive Tactics: An Integrative Approach. Cambridge University Press, New York.

Parker, G.A., 1970. Sperm competition and its evolutionary consequences in the insects. Biol. Rev. 45, 525-567.

Parker, G.A., Ball, M.A., 2005. Sperm competition, mating rate and the evolution of testis and ejaculate sizes: a population model. Biol. Lett. 1, 235-238.

Svensson, O., 2004. Sexual selection in Pomatoschistus - nests, sperm competition, and parental care. PhD Thesis, Stockholm University, Stockholm, Sweden.

Taborsky, M., 1998. Sperm competition in fish: 'bourgeois' males and parasitic spawning. Trends Ecol. Evol. 13, 222-227.

Tomkins, J.L., Simmons, L.W., 2002. Measuring relative investment: a case study of testes investment in species with alternative male reproductive tactics. Anim. Behav. 63, 1009-1016.

Tvedt, H.B., Benfey, T.J., Martin-Robichaud, D.J., Power, J., 2001. The relationship between sperm density, spermatocrit, sperm motility and fertilization success in Atlantic halibut, Hippoglossus hippoglossus. Aquaculture 194 191-200.

Wickett, R.G. Corkum, L.D. 1998. Nest defense by the nonindigenous fish, the round goby, Neogobius melanostomus (Gobiidae), on a shipwreck in western Lake Erie. Can. Field Nat. 112, 653-656.

Yanagimachi, R., Cherr, G.N., Pillai, M.C., Baldwin, J.D., 1992. Factors controlling sperm entry in the micropyles of salmonid and herring eggs. Devel. Growth Differen. 34 447-461. 